\title{
Individual preferences towards nuclear energy: the transient residency effect
}

\author{
Davide Contu ${ }^{1}$, Susana Mourato ${ }^{2}$, Ozgur Kaya ${ }^{3}$
}

\begin{abstract}
Nuclear energy is an energy source that is usually unfavorable among the public due to its inherent risks. However, it presents a number of benefits, including the possibility to reduce emissions and the contribution to tackle climate change. Among the countries adopting nuclear energy, the United Arab Emirates (UAE) is unusual in that a large share of its residents consists of expatriates who live only part of their lives in the country with no (or highly unlikely) access to citizenship. This distinctive population structure offers the opportunity to investigate the effect of transient residency on acceptance and preferences towards nuclear energy. We conducted this investigation by designing a stated preferencesbased survey, targeting an online nationwide sample. The survey collected information on socioeconomic characteristics and attitudes, including views on perceived risks and benefits of nuclear energy, views towards different energy sources, and life satisfaction. Results indicate that transient individuals, especially those who are more satisfied with their lives in the UAE, are significantly less likely to oppose the construction of new nuclear plants. These individuals are characterized by a more positive perception of benefits over risks arising from nuclear energy. Policy implications are discussed. Keywords: Nuclear energy, social acceptability, transient resident, choice experiments, willingness to accept, UAE JEL Code: C9, D62, D82, Q48, Q51, Q58
\end{abstract}

\section{Introduction}

A number of countries in the Middle East-including the UAE-have announced their plans to invest in nuclear energy (El-Katiri 2012). UAE's decision to invest in nuclear energy is motivated by forecasted growth in energy demand. Although the nation has one of the

\footnotetext{
${ }^{1}$ Davide Contu, Canadian University Dubai, UAE, e-mail: davide.contu@cud.ac.ae

${ }^{2}$ Susana Mourato, The London School of Economics and Political Science, UK, e-mail: s.mourato@1se.ac.uk

${ }^{3}$ Ozgur Kaya, American University of Sharjah, UAE, Corresponding author: email: okaya @aus.edu
} 
world's largest reserves of hydrocarbons (Masdar/IRENA 2015), sustained population and economic growth has significantly expanded energy demand (Mezher et al. 2012; Jayaraman et al. 2015). Therefore, it is necessary to modify the energy mix which means increasing the share of renewable energy sources and considering nuclear energy (AlFarra and Abu-Hijleh 2012; Jayaraman et al. 2015; Betancourt-Torcat and Almansoori 2015).

With the aim of developing a successful nuclear program, the UAE has signed bilateral nuclear-cooperation agreements with the US, Korea and France. In addition, it concluded memoranda of understanding with the UK and Japan, consulted leading nuclear suppliers and made clear its willingness to forsake a full nuclear cycle ${ }^{4}$ (Early 2010; Strategic Comments 2010). This strategy has made the UAE the first Arab state to make tangible progress towards using nuclear power for electricity generation.

Successful implementation of a nuclear energy programme usually requires social acceptance of nuclear energy (Hammond 1996; Ansolabehere et al. 2003; Weisser et al. 2008; Schneider et al. 2016). Arguably, this is of particular relevance in countries where citizens can vote, request referenda, or veto government's choices in terms of energy policy. Yet, even in countries where referenda are currently not in place, opposition to nuclear energy may lessen the likelihood of implementation and/or increase its costs. In the UAE, the government explicitly makes the welfare and happiness of residents objects of its policy. The Emirates Nuclear Energy Corporation (ENEC), the entity responsible for the deployment and operation of the UAE nuclear energy programme, acknowledges the importance of public opinion, as demonstrated by polls commissioned since 2011 (ENEC 2011) and open public forums hosted since 2010 (ENEC 2014, 2017).

\footnotetext{
${ }^{4}$ Spent fuel is planned to be stored in dry storage systems after a phase of storage in spent fuel pools (Al Saadi and Yi 2015).
} 
The UAE population exceeds 9 million, with non-nationals accounting for at least $80 \%$ of the total (Koch 2016). There is currently neither access to citizenship nor unconditional permanent residency for almost all non-UAE nationals ${ }^{5}$ : at some point, expatriates would most likely have to leave the country ${ }^{6}$. While this is true of most expatriates, they are otherwise a highly heterogeneous group. The expatriate population comprises individuals with different backgrounds, nationalities, culture and social status (Hills and Atkins 2013) and includes members facing different challenges and rewards in the workplace (Koch 2016).

This study employs a stated preference technique, choice experiments, implemented through a nation-wide survey to estimate the willingness to accept (WTA) nuclear power plants in the UAE. In a choice experiment, one does not directly ask about monetary valuations attached to different aspects of choice (i.e. about willingness to pay (WTP) or willingness to accept (WTA)). Instead, respondents choose the scenario they prefer and if one of the attributes associated with that choice is monetary, WTP or WTA can be inferred. Therefore, this methodology allows the derivation of the implicit price of each of the other attributes (i.e. marginal WTP or WTA), as well as the total welfare change provided by various scenario options.

In addition to the choice experiment, the survey included questions on socio-economic characteristics, attitudes towards different energy sources, and life satisfaction. Life satisfaction is one of the subjective measures of welfare associated with the term 'subjective well-being', which is employed to assess experienced utility (Kahneman and Krueger 2006) and value non-market goods (Van den Berg and Ferrer-I-Carbonell 2007; Dolan and Metcalfe

\footnotetext{
${ }^{5}$ The validity of stay on a residence visa varies according to its type and the sponsor. It can be for 1,2 or 3 years. According to a change in 2019, a residence visa can also be issued for 5 and 10 years subject to certain conditions (The UAE Government portal, https://government.ae/en/information-and-services/moving-to-the-uae/how-to-become-a-resident-in-the-uae).

${ }^{6}$ The presence of a high share of transient residents relative the share of national citizens is a common feature across the GCC countries with the exception of Oman and Saudi Arabia (IOM 2018).
} 
2012; Levinson 2012; MacKerron 2012; MacKerron and Mourato 2013). Transient residents might lack shared hopes and desires for the future of the society (Forstenlechner and Rutledge 2011). Yet, as discussed in Koch (2016), nationalism is exhibited by non-citizens in the UAE, for which the country might represent a 'home away from home'. To this end, we included questions on life satisfaction into our analysis to assess whether expatriates experienced an overall improvement in their lives after coming to the UAE.

All in all, this research provides insights about factors influencing social acceptance of nuclear energy in a unique country setting where a very large portion of its residents consists of transient residents. Specifically, we aim to test the following hypothesis: a) whether transient residents are more or less likely to oppose the implementation of nuclear energy projects; b) whether the impact of transient residency is significantly greater among residents who feel more satisfied with their life in the UAE; c) whether transient residents, compared to non-transient residents, are more likely to perceive more benefits as opposed to risks of nuclear energy. The rest of the paper is organized as follows: section 2 presents background information on public attitudes towards nuclear energy; section 3 describes the methodology detailing the choice experiment and the survey design; section 4 lays out the data and results; finally, section 5 concludes.

\section{Social acceptance of nuclear energy}

In the early 1980s the concept of NIMBY (Not in my backyard) was put forward to explain negative views towards nuclear energy and other potential threats with the argument that selfish citizens would oppose the siting of problematic facilities in their neighborhood whilst not opposing them elsewhere (Letcher and Vallero 2019). Since then, decades of research have deepened our understanding around the determinants of acceptance and 
opposition of energy sources. Perceived risks and benefits of nuclear energy seem to represent major determinants (Ansolabehere et al. 2003; Ansolabehere and Konisky 2009; Bronfman et al. 2012; Choi et al. 1998; De Boer and Catsburg 1988; Groot and Steg 2008; Greenberg 2009; Groot et al. 2013; Kato 2006; Rosa and Dunlap 1994; Zhu et al. 2016; Wu 2017). Additionally, trust towards regulatory agencies seems key in shaping acceptance (Ansolabehere and Konisky 2009; Greenberg 2009; Siegrist and Cvetkovich 2000; Siegrist et al. 2000; Greenberg and Truelove 2011; Bronfman et al. 2012). Proximity to nuclear plants is also considered as an important factor. In communities with established projects, there is evidence of a more positive view, with perceived risks decreasing as proximity increases (Venables et al. 2012). More generally, people living in countries with nuclear plants in operation tend to state more positive views, with greater shares of respondents indicating advantages outweigh risks of such programmes (Kovacs and Gordelier 2009). When nuclear energy projects are explicitly linked to the possibility of tackling climate change, acceptance seems to be fostered (Visschers et al. 2011). On the other hand, evidence suggests that individuals who are more concerned about the environment, besides climate change, would opt for renewables over nuclear (Ertör -Akyazi et al. 2012). Finally, the information available to the respondents could affect social acceptance. In particular, providing information on benefits and risks seems to reduce opposition towards nuclear energy (Jun et al. 2010; Zhu et al. 2016).

There is scant existing research on social acceptance of nuclear energy in the UAE and, more broadly, in the Gulf Cooperation Council (GCC) countries. Since 2011, global market research companies, commissioned by ENEC, conducted a number of national polls. In 2011, $85 \%$ of the UAE residents sampled believed that a peaceful nuclear energy program was 
important for the nation according to a research by TNS (ENEC 2011). The latest poll, conducted in 2018 by Nielsen, revealed some of the highest favorability rates for nuclear energy, with $91 \%$ of the sampled residents stating that a peaceful energy program is important for the nation (ENEC 2019). Furthermore, according to this poll, support for the construction of peaceful nuclear energy plants in the UAE reached a level of $85 \%$, whereas $75 \%$ of the sampled respondents believed that the benefits of nuclear energy outweighed risks. With regards to other GCC countries, data from OECD (2010) and Globescan (2005) showed limited support towards nuclear energy in Saudi Arabia, country where the share of nationals is much greater than the share of expatriates.

\section{Methodology}

\subsection{Choice experiments}

Choice experiments (CE), a stated preference technique, are widely used in Environmental Economics (Hanley et al. 2001; Louviere et al. 2000). This method allows one to estimate economic valuations of goods that are not exchanged in markets, based on choices made in a hypothetical setting. We utilize choice experiments to measure preferences towards nuclear plants. Respondents are presented with a series of choice tasks, where nuclear projects with differing attributes are described. Next, they are asked to choose, in each choice task, their most preferred scenario. Each project or scenario is characterized by a set of attributes, and each attribute is characterized by a set of levels. Applications of choice experiment studies to nuclear energy are still scant, and the few exceptions include Contu et al. (2016), Cicia et al. (2012), Itaoka et al. (2006). In this study, the choice experiment scenarios requested respondents to imagine they had a chance to choose between a series of options regarding the construction of current generation nuclear power plants in the UAE. 
We presented four choice tasks, each involving a comparison of two hypothetical nuclear power projects and a third option, namely none of the two. The hypothetical projects had four attributes. An example of such choice tasks is displayed in Figure 1.

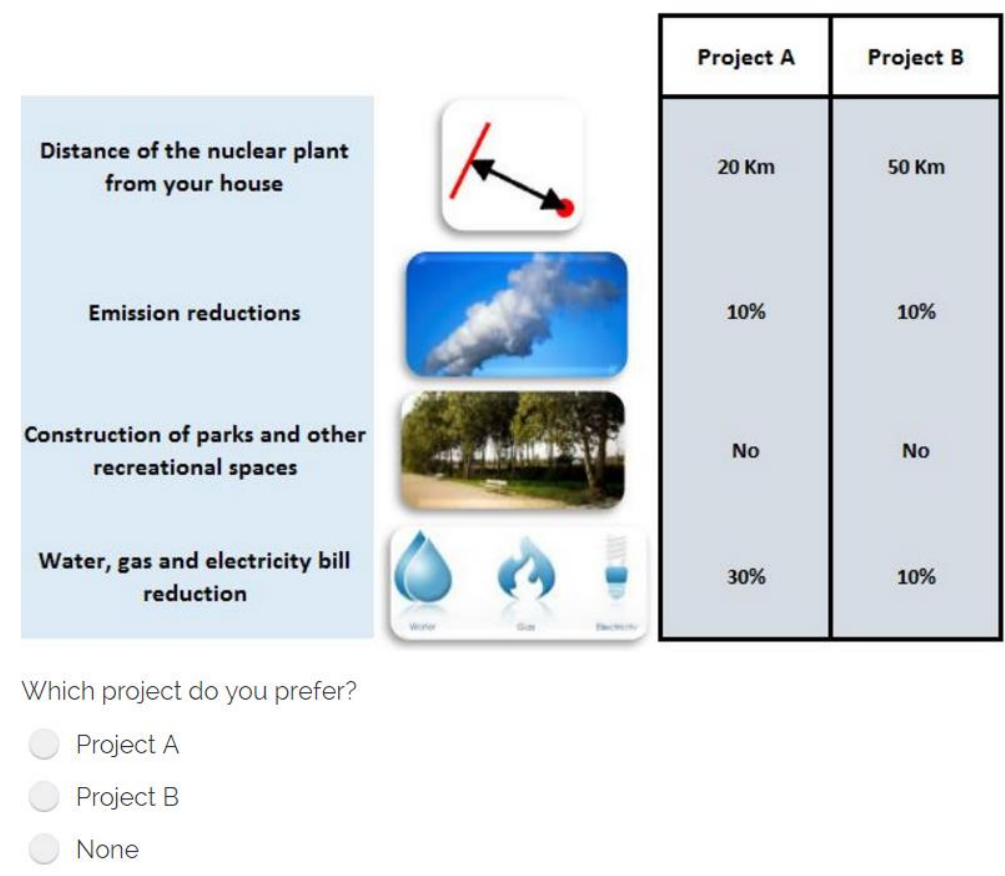

Figure 1: Example of choice task

The four chosen attributes were: 'atmospheric emission reductions', 'distance from the nuclear power plant', 'construction of parks or other recreational spaces' and 'water, gas and electricity bill reductions'. The selection of attributes and levels was informed by previous studies conducted in Italy and the UK (Contu et al. 2016), as well as by literature review. Table 1 shows the attributes and how many levels each attribute have. The attributes 'distance from the nuclear plant' and 'emission reductions' proved to be of significant relevance in analogous studies carried out in Italy and UK (Strazzera et al. 2012, Contu et al. 2016). Distance is a key element considering the nuclear plants pose potential threats to the environment (Beheshti 2011) and human health (Fairlie 2013). 'Construction of parks and 
other recreational spaces' was included as an attribute so as to introduce the potential public benefits typically associated with the construction of nuclear plants (Yamane et al. 2011; Gregory et al. 1991; Mansfield et al. 2002). Finally, 'water, gas and electricity bill reduction' was incorporated as the monetary attribute (Strazzera et al. 2012). A combination of water, gas and electricity bill reduction, as opposed to a simple electricity bill reduction, was included due to the relatively low prices of electricity bill in the UAE (Mezher et al. 2012; Griffiths and Mills 2016).

Table 1. Attributes and levels of the choice experiments

\begin{tabular}{cc}
\hline Attributes & Levels \\
\hline Distance from the nuclear plant & $\begin{array}{c}20,50,100, \text { or } 200 \mathrm{Km} \text { from } \\
\text { the city of residence/house }\end{array}$ \\
Atmospheric emission reduction & $20 \%, 10 \%$ or no reduction \\
Construction of parks/recreational spaces & Yes or No \\
Water, Gas and Electricity bill reduction & $30 \%, 20 \%, 10 \%$ or no \\
& reduction \\
\hline
\end{tabular}

Given four attributes and their levels, with two nuclear project options per choice task, the total number of possible experimental choice task combinations is $9216^{7}$. This is clearly excessive, so it was therefore necessary to reduce the number of presented choice tasks by means of an experimental design. A Bayesian efficient design ${ }^{8}$ (Sándor and Wedel 2001;

\footnotetext{
74 distance levels $* 3$ emission reduction levels $* 4$ bill reduction levels $* 2$ public investments $=96$ scenarios. As each choice card comprises a pair of scenarios, the total number of all possible pairs is $96 * 96=9216$.

${ }^{8}$ The Bayesian approach requires that the efficiency of a design to be evaluated over many different draws taken from the prior parameter distributions assumed in generating the design. The Bayesian efficiency of a design is, then, calculated by using simulation methods to approximate the expectations for differing designs (Bliemer et al. 2008).
} 
Bliemer et al. 2008; Rose and Bliemer 2009) was prepared. Priors were derived from analogous CE studies conducted in Italy and UK (Strazzera et al. 2012, Contu et al. 2016). The final design consists of 8 blocks of choice experiments with 4 choice tasks in each block, for a total of 32 pairs of projects presented, along with a 'none' option (design available upon request). Hence, the number of combinations taken into consideration totaled 256. The design is prepared with the goal to minimize the standard errors of the preference coefficients given the priors inputted, which in a Bayesian approach follow a distribution rather than being fixed. The combinations produced tend to avoid the inclusion of choice situations where the choice is dominated or most likely to be predicted given the value of the priors and the attributes' levels. The design was generated with the software NGENE.

\subsection{Econometric models}

When analyzing choice experiment data, we estimate the following utility function ${ }^{9}$ for our econometric analysis ${ }^{10}$ :

$$
\begin{aligned}
V_{i j}=\beta_{1} A S C+ & \beta_{2} \text { Distance }_{200 \mathrm{Km}}+\beta_{3} \text { Distance }_{100 \mathrm{Km}}+\beta_{4} \text { Distance }_{50 \mathrm{Km}} \\
& +\beta_{5} \text { Emission }_{20 \%}+\beta_{6} \text { Emissions }_{10 \%}+\beta_{7} \text { Parks }+\beta_{8} \text { Bill }
\end{aligned}
$$

ASC refers to the alternative specific constant indicating which of the alternatives is the 'none' option. Therefore, the coefficient attached to it, $\beta_{1}$, describes whether respondents are more or less likely to choose none of the projects. This is an indication of broad acceptance ( $\beta_{1}$ negative) or opposition ( $\beta_{1}$ positive) towards nuclear energy. Yet, the 'none' option could be chosen due to reasons other than acceptance or opposition, such as lack of preferred alternative or difficulty of the tasks.

\footnotetext{
${ }^{9}$ Utility of individual $i$ for alternative $j$ is given by: $U_{i j}=V_{i j}+\varepsilon_{i j}$ where $V_{i j}$ and $\varepsilon_{i j}$ are the deterministic and stochastic components, respectively, and $V_{i j}$ represents $V_{i j}=\sum_{k} \beta_{i k j} X_{i k j}^{\prime}$.

${ }^{10}$ Variable codes are presented in Appendix, Table A1.
} 
The error term of this estimated utility function is assumed to follow a Type I extreme value distribution where errors are distributed identically and independently for all observations. Accordingly, we use a Multinomial Logit model (MNL) to estimate the coefficients. Because the coefficients represent marginal utilities, a ratio of coefficients (when one of the attributes is money) provides a monetary valuation for the other attribute.

Two assumptions associated with the MNL model may be troublesome. First, the MNL model assumes independence of irrelevant alternatives. The assumption is restrictive, but MNL is nevertheless widely used. Second, the MNL model assumes preference homogeneity. Given these difficulties, we check for robustness by employing both a latent class model (Boxall and Adamowicz 2002) and a Random Parameters Logit (RPL) model. According to the latent class model approach, parameters are the same within and different between classes of observation. The RPL model overcomes taste variation issues by assuming preference heterogeneity to follow a continuous distribution and that does not exhibit independence of irrelevant alternatives (Revelt and Train 1998; McFadden and Train 2000).

The latent class (LC) approach represents an alternative way to model preference heterogeneity (Boxall and Adamowicz 2002; Greene and Hensher 2003). As opposed to the RPL model where heterogeneity is modelled in a continuous fashion, the LC model assumes the existence of a given number of segments of preferences, different between and same within. The deterministic component of the utility function, conditional on each segment $\mathrm{s}$, is as follows:

$$
\begin{gathered}
V_{i j \mid s}=\beta_{1 \mid s} A S C+\beta_{2 \mid s} \text { Distance }_{200 \mathrm{Km}}+\beta_{3} \text { Distance }_{100 \mathrm{Km}}+\beta_{4 \mid \mathrm{S}} \text { Emission }_{20 \%} \\
+\beta_{5 \mid s} \text { Emissions }_{10 \%}+\beta_{6 \mid s} \text { Parks }+\beta_{7 \mid S} \text { Bill }
\end{gathered}
$$


Finally, in order to inspect and analyze data relative to perceived benefits and risks of nuclear energy, we employ factor analysis. Additional details on the econometric models used in this study are available in Appendix C.

\section{Data, descriptive statistics and results}

\subsection{Data}

This study uses survey data collected from 1,961 respondents residing in the UAE. Given that we had four choices in each choice experiment, the total number of observations generated amounts to 7844 for the choice experiment data. The data contain information on socio-economic characteristics and attitudes, including views on different energy sources, perceived risks and benefits of nuclear energy, and life satisfaction. Quotas on age, gender and nationality group were set so as to be in line with the target population: UAE residents aged 18 and more.

We administered the questionnaire online between June and July 2015 using a market research company (YouGov), who recruits members of the panel and receive surveys. Respondents could complete the survey in English or Arabic, based on their preference. The survey flow was designed to incentivize the respondents to think carefully about energy and climate change issues before they participated in the choice experiment exercise focusing on nuclear energy. The survey was prepared in Gryphon, survey programming tool used by YouGov. 10 face-to-face pilots were conducted to test the flow and content. The finalized survey was initially soft-launched with 50 respondents and subsequently fully launched after satisfactory inspection of the initial data collected. All the surveys' views were optimized for both laptop and mobile view (Appendix B shows key screens from the survey, whereas additional information is available upon request). 
62 different nationalities took part in the survey, the majority belonging to India (34\%), Pakistan (11\%), Philippines (10\%) and the UAE (10\%). In order to define the segment of transient expatriate residents, we rely on stated intention to leave the country. We consider as transient those who intend to leave within the next ten years. Overall, this group constitutes $38 \%$ of the total sample and $42 \%$ of the expatriates. Other expatriates, who do not plan to leave the UAE in the next ten years, make up $52 \%$ of the sampled respondents.

Table 2 presents summary statistics for the complete sample and for the following subgroups considered throughout the study: UAE nationals, transient and other expatriates. In line with the population structure of the UAE, only $20 \%$ of the sampled respondents were born in the UAE. This share grows substantially among UAE nationals (64\%). The lowest share of those who were born in the country is among transient expatriates $(6 \%)$. UAE nationals are also, unsurprisingly, the group of respondents who have been living longest in the country: 6 in 10 have stayed for more than 20 years. In contrast, only $7 \%$ of transient residents have stayed in the country for so long. Considering employment, almost 8 out of 10 transient residents work full time. This is the highest share across the groups considered, whereas Emiratis have the lowest share (58\%). Emiratis and transient expatriates share the lowest level of unemployment (4.6\%). $65 \%$ of the respondents are male and average age is 33.8 years. However, a significantly greater share of women (38\%) was sampled among the group of other expatriates. Almost half of the sample consists of respondents who are married with children (47\%), while $35 \%$ are single. 
Table 2. Sample structure by socio-demographic variables (\% reported)

\begin{tabular}{|c|c|c|c|c|}
\hline & All & Transients $^{\mathrm{a}}$ & Emiratis & $\begin{array}{l}\text { Other } \\
\text { expats }\end{array}$ \\
\hline & $\mathrm{N}=1961$ & $\mathrm{~N}=738$ & $\mathrm{~N}=197$ & $\mathrm{~N}=1026$ \\
\hline \multicolumn{5}{|c|}{ Gender } \\
\hline Male & 64.7 & 67.3 & 70.1 & 61.8 \\
\hline Female & 35.3 & 32.7 & 29.9 & 38.2 \\
\hline \multicolumn{5}{|c|}{ Marital status } \\
\hline Single-never married & 34.5 & 37.1 & 32.5 & 33 \\
\hline Married without kids & 15.8 & 17.6 & 13.7 & 14.8 \\
\hline Married with kids & 47.4 & 43 & 49.2 & 50.2 \\
\hline Divorced & 2 & 2 & 4.6 & 1.6 \\
\hline Widow/widower & 0.3 & 0.3 & 0 & 0.4 \\
\hline \multicolumn{5}{|c|}{ Employment } \\
\hline Working full time & 70 & 78.2 & 58.4 & 66.4 \\
\hline Working part time & 8.7 & 8.5 & 19.8 & 6.6 \\
\hline Full time student & 4.8 & 3.4 & 8.6 & 5.2 \\
\hline Retired & 0.8 & 0.7 & 2.5 & 0.6 \\
\hline Full-time home-maker or housewife & 8.3 & 4.2 & 5.1 & 11.8 \\
\hline Unemployed & 6.6 & 4.6 & 4.6 & 8.5 \\
\hline Other & 0.8 & 0.4 & 1 & 1 \\
\hline \multicolumn{5}{|c|}{ Were you born in the UAE? } \\
\hline Yes & 20.2 & 6.1 & 64 & 21.9 \\
\hline No & 79.8 & 93.9 & 36 & 78.1 \\
\hline
\end{tabular}

Less than 1 year

$1-2$ years

3-4 years

5-6 years

$7-8$ years

9-10 years

$11-15$ years

16-20 years

21-30 years

More than 30 years

\section{For how many years have you been living in the UAE}

\begin{tabular}{cccc}
8 & 10.7 & 2.5 & 7 \\
11.4 & 18 & 3.6 & 8.2 \\
12.1 & 17.8 & 4.6 & 9.5 \\
9.8 & 11.1 & 5.6 & 9.6 \\
10.7 & 11 & 5.1 & 11.5 \\
6.7 & 6.9 & 3.6 & 7.1 \\
10.1 & 10.7 & 5.6 & 10.6 \\
8.7 & 6.5 & 10.2 & 9.9 \\
12.7 & 5 & 23.9 & 16.2 \\
9.8 & 2.3 & 35.5 & 10.3 \\
\hline
\end{tabular}

\section{How long are you planning to stay in the UAE}

Less than 3 months

$1.6 \quad 4.1$

$3-6$ months

1.2

$6-12$ months

1.5

$1-2$ years

7.1

10.5

$3-4$ years

9.9

$7-10$ years

8.4

12.5

More than 10 years

28.1

Do not know
4.1

3.7

17.2

26

25.1

21.3

0

0

0

\begin{tabular}{cc}
1 & 0 \\
1.5 & 0 \\
1.5 & 0 \\
6.6 & 0 \\
7.1 & 0 \\
4.6 & 0 \\
3.6 & 0 \\
11.2 & 21.8 \\
54.3 & 43.4 \\
8.6 & 34.8 \\
\hline
\end{tabular}

${ }^{\text {a}}$ Respondents who stated to intend to leave the UAE within ten years. 
With regards to monthly personal income, the highest share is observed for the category AED 5,001-AED 10,000 (22\%), followed by AED 2,001-AED $5000(19 \%)^{11}$. More transient residents have a lower income: $38 \%$ up to $5000 \mathrm{AED}$; whereas Emiratis have the highest income, with $35.5 \%$ indicating an income of 25000 AED or more.

Respondents were asked whether the risks of nuclear energy are justified by its benefits, including its contribution to decreasing the impact of climate change. A slightly higher share of transient residents believe so (36.6\%), as opposed to UAE nationals (30\%) and other expatriates (28\%). Solar/photovoltaic energy seems to be the most favored energy source among the respondents. Behind renewable energy, we find nuclear. Although $11 \%$ of the respondents would not want the UAE to invest anything on nuclear energy, 26\% would like the nation to invest a lot on it. A similar share, 24\%, selected 'I do not know'.

We also assessed potential risks and benefits associated with nuclear energy. For each risk and benefit enumerated, respondents were probed to think about nuclear energy in the UAE and nuclear energy in general. The UAE is associated with significantly lower perceived risks, with no significant difference in perceived benefits found. A difference in ratings given to risks and benefits in the UAE emerges comparing different groups of respondents. When compared to UAE nationals, transient residents attach a greater likelihood to both risks and benefits. (Figures 2 and 3$)^{12}$.

\footnotetext{
${ }^{11}$ The UAE dirham is pegged to the US dollar (fixed at a rate of AED 3.67 to US \$1) since 1997 to date. So AED 5,00110,000 is equivalent to US $\$ 1360$ - \$2720. Also, note that as of November 2019 there is no income tax in the UAE.

12 This is further explored in Section 4.3 by means of factor analysis.
} 


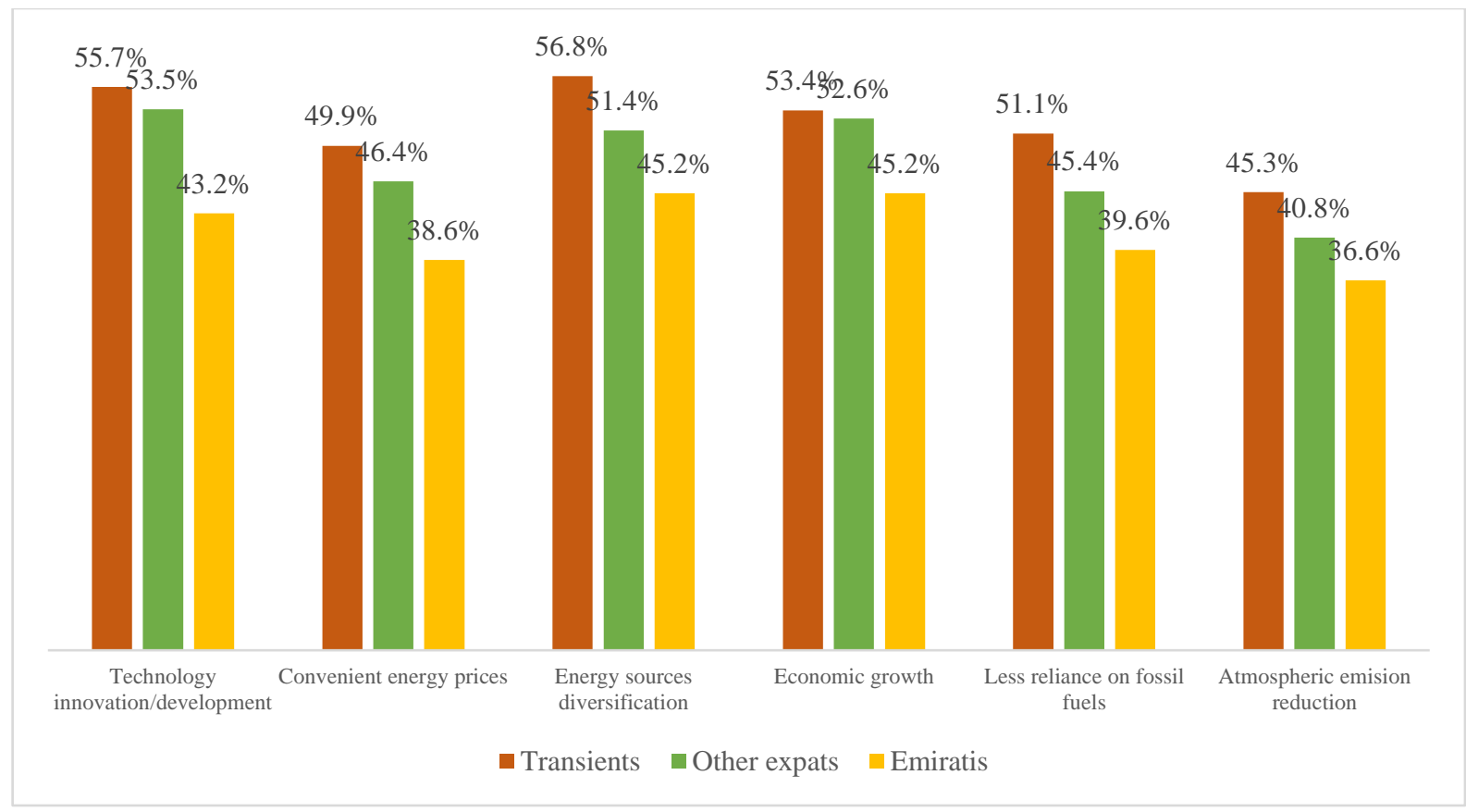

Figure 2: Perceived benefits of nuclear energy in the UAE-sum of likely \& very likely

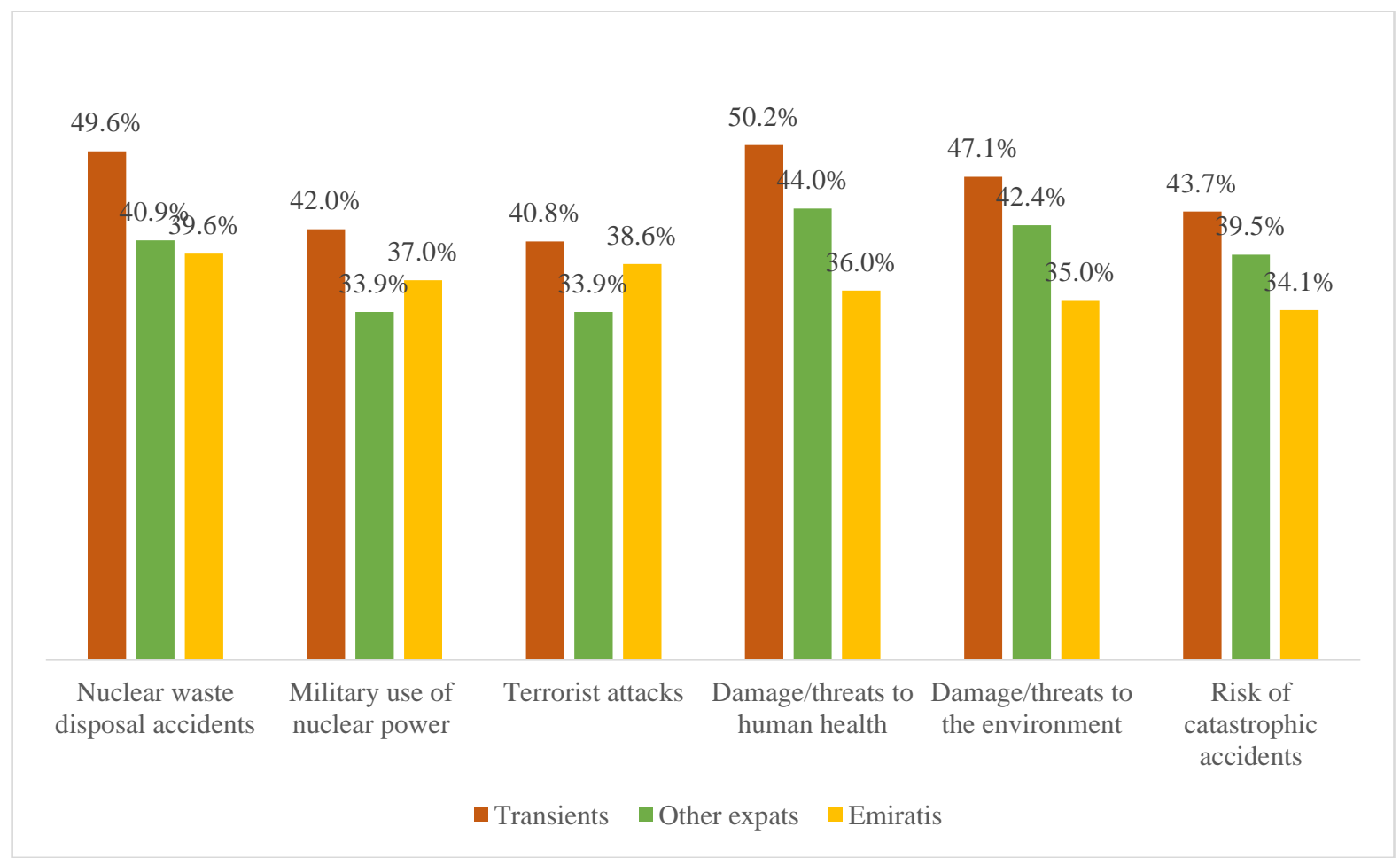

Figure 3: Perceived risks of nuclear energy in the UAE-sum of likely \& very likely 
Overall life satisfaction in the UAE is greater among Emiratis, with an average score of 7.6 on a 10-point scale. $35 \%$ of UAE nationals selected a score of 10 (Very satisfied), compared to just $7.3 \%$ of transient residents and $16.4 \%$ of other expatriates. Across the whole sample, average life satisfaction is 6.8 (Figure 4). According to the World Happiness Report (2016), the UAE average score on a similar question is 6.6.

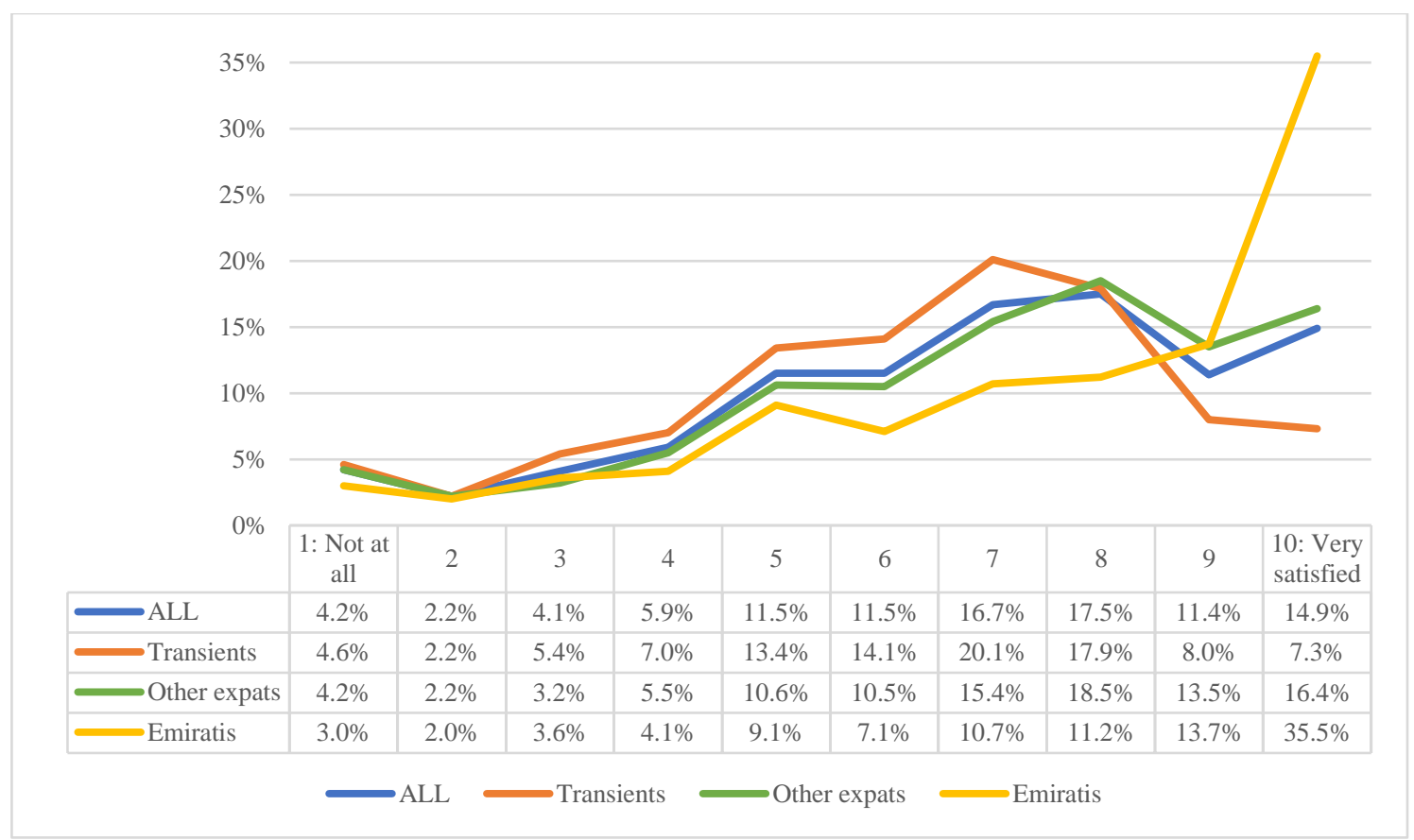

Figure 4: How satisfied are you, overall, with your life in the UAE?

\subsection{Choice experiment results}

We start our econometric analysis of choice experiment data with MNL and RPL models. For the latter model, all parameters are assumed to be normally distributed excepting the monetary attribute's coefficient, which is held fixed (Table 3). Although both models have similar implications about preferences, the RPL model seems to be preferable in terms of model fit as it reveals a substantial amount of preference heterogeneity. Both of these models show the presence of a positive attitude towards nuclear options in general, as 
indicated by the negative and significant coefficient attached to the alternative specific constant (ASC).

Table 3. MNL and RPL models. Dependent variable: Choice

\begin{tabular}{|c|c|c|c|c|c|}
\hline & MNL & RPL & RPL & MNL & RPL \\
\hline Variable & \multicolumn{2}{|c|}{ Coeff. (S.e.) } & S.D. & \multicolumn{2}{|c|}{$\begin{array}{c}\text { Monetary Valuations } \\
\text { (AED) }\end{array}$} \\
\hline ASC & $\begin{array}{c}-.312 * * * \\
\quad(.065)\end{array}$ & $\begin{array}{c}-2.46^{* * *} \\
(.179)\end{array}$ & $\begin{array}{c}4.10 * * * \\
(.186)\end{array}$ & -610.1 & -4004.7 \\
\hline Distance: 200 Km & $\begin{array}{l}.495^{* * * *} \\
(.048)\end{array}$ & $\begin{array}{l}.674 * * * \\
(.055)\end{array}$ & $\begin{array}{c}.536 * * * \\
(.165)\end{array}$ & 966.4 & 1094.1 \\
\hline Distance: $100 \mathrm{Km}$ & $\begin{array}{l}.317 * * * \\
(.051)\end{array}$ & $\begin{array}{l}.471 * * * \\
(.057)\end{array}$ & $\begin{array}{l}.023 \\
(.113)\end{array}$ & 619.9 & 764.8 \\
\hline Distance: 50 Km & $\begin{array}{l}.000 \\
(.047)\end{array}$ & $\begin{array}{c}.073 \\
(.054)\end{array}$ & $\begin{array}{l}.325 * \\
(.184)\end{array}$ & $\rightarrow 0$ & $\rightarrow 0$ \\
\hline $\begin{array}{l}\text { Emission Reduction: } \\
20 \%\end{array}$ & $\begin{array}{c}.157 * * * \\
(.042)\end{array}$ & $\begin{array}{c}.191 * * * \\
(.045)\end{array}$ & $\begin{array}{c}.044 \\
(.133)\end{array}$ & 308.3 & 310.2 \\
\hline $\begin{array}{l}\text { Emission Reduction: } \\
10 \%\end{array}$ & $\begin{array}{l}.125^{* * * *} \\
(.037)\end{array}$ & $\begin{array}{c}.166^{* * *} \\
(.039)\end{array}$ & $\begin{array}{l}.011 \\
(.115)\end{array}$ & 245.8 & 270.3 \\
\hline Parks & $\begin{array}{l}.114^{* * * *} \\
(.026)\end{array}$ & $\begin{array}{l}.179 * * * \\
(.032)\end{array}$ & $\begin{array}{l}.008 \\
(.082)\end{array}$ & 224.4 & 291.2 \\
\hline Bill Reduction (AED) & $\begin{array}{c}.0005^{* * *} \\
(.000)\end{array}$ & $\begin{array}{c}.0006 * * * \\
(.000)\end{array}$ & / & / & l \\
\hline Log-Likelihood & -8143.71 & -7009.40 & & & \\
\hline R squared & 0.05 & 0.18 & & & \\
\hline Observations & 7844 & 7844 & & & \\
\hline
\end{tabular}

Level of significance: $* 10 \%, * * 5 \%, * * * 1 \%$. Robust standard errors in parenthesis. b: fixed coefficient. 
As expected respondents prefer nuclear projects located further away from their city of residence. They positively value emission reductions, the building of parks and bill reductions. According to both models all estimated coefficients are significant, with the exception of $\beta_{4}$ (nuclear plant located $50 \mathrm{Km}$ away). While there are non-linear effects attached to distance, no significant difference is present when comparing 20 and $50 \mathrm{Km}$.

The monetary valuations, shown in the last two columns of Table 3 for the MNL and RPL respectively, represent willingness to accept compensation for a worse level of the attribute considered. Considering RPL estimates, we estimated that respondents would prefer nuclear plants built away from their area of residence, as they would be willing to forgo around 1100 AED (US \$300) a year for a nuclear plant located $200 \mathrm{Km}$ away rather than 20 km away. This reduces to 765 AED (US \$200) for a distance of $100 \mathrm{Km}$. Overall, distance seems to be a key attribute for the respondents. Emission reductions are positively valued too, around 310 AED (US \$85) for 20\% emissions reduction. Similarly, the building of parks is valued around 300 AED (US \$80).

When the monetary attribute's coefficient is fixed, as in the RPL model above, we assume that all individuals have the same preferences for the monetary attribute, which is unrealistic. Thus, in order to allow monetary attribute preferences to be heterogeneous, we can specify this coefficient to be log-normally distributed. With this specification, we make sure that WTP measures have defined moments since the monetary attribute coefficient is constrained to be positive, but the resulting WTP distribution can be highly skewed. One way to overcome this problem is to estimate the mixed logit model in WTP space (Train and Weeks 2005; Meijer and Rouwendal 2006; Hole and Kolstad 2012). Accordingly, we estimate an RPL model in willingness to pay space (Table 4), where the monetary attribute is 
assumed to be distributed according to a positive log-normal distribution; remaining coefficients are assumed to be normally distributed. When allowing for heterogeneity in the cost parameter, monetary valuations are substantially lower. Individuals are willing to forgo only 578 AED (US \$157) for a nuclear plant built $200 \mathrm{Km}$ away, 483 AED if $100 \mathrm{Km}$ away. Furthermore, emission reductions are not valued more than 62 AED (for a $10 \%$ decrease). Finally, the building of parks is valued 122 AED (US \$33). Although the monetary valuations are more conservative in this case, this model with an additional parameter does not present a superior goodness of fit as opposed to the previous RPL where the cost parameter was set fixed.

Table 4. RPL model (WTP space). Dependent variable: Choice

\begin{tabular}{|c|c|c|c|c|}
\hline Variable & $\begin{array}{c}\text { Monetary } \\
\text { Valuations } \\
\text { (AED) }\end{array}$ & t-statistic & S.D. & t-statistic \\
\hline ASC & -1318.2 & 1.09 & 28.8 & 0.39 \\
\hline Distance: $200 \mathrm{Km}$ & 578.2 & 1.1 & 85.5 & 0.32 \\
\hline Distance: 100 Km & 482.9 & 0.8 & 64.6 & 0.16 \\
\hline Distance: $50 \mathrm{Km}$ & 77.5 & 4.2 & 19.3 & 0.18 \\
\hline $\begin{array}{l}\text { Emission Reduction: } \\
20 \%\end{array}$ & 51.3 & 0.46 & 67.4 & 2.3 \\
\hline $\begin{array}{l}\text { Emission Reduction: } \\
10 \%\end{array}$ & 62 & 1.36 & 13.0 & 0.16 \\
\hline Parks & 122.4 & 76.9 & 3.37 & 0.23 \\
\hline Log-Likelihood & -7365.105 & & & \\
\hline R squared & 0.15 & & & \\
\hline Observations & 7844 & & & \\
\hline
\end{tabular}


Given the hypotheses to be tested, we also assess the presence of differences in preferences between different respondent groups, specifically the expatriates who are likely to leave the UAE within 10 years and the ones that are more satisfied with their life in the UAE. Accordingly, we estimated an RPL model using a heterogeneity decomposition where we used two sets of interactions for each utility's coefficient ${ }^{13}$. In the first set of interactions, we used a dummy variable identifying whether the respondent is an expatriate likely to leave the UAE within 10 years (a transient resident). In the second set of interactions, we used a dichotomous variable identifying whether the respondent is an expatriate more satisfied with his/her life in the UAE (regardless of whether he or she classifies as transient or not). For both sets of interactions, we found a significant effect with respect to the ASC: transient respondents and those more satisfied with their lives in the UAE are associated with a lower coefficient, translating into a lower probability of choosing none of the projects. In addition, transient residents are also associated with significantly lower coefficients for the attribute 'distance', thereby confirming a lessened degree of opposition (Table 5).

\footnotetext{
${ }^{13}$ All utility function coefficients are assumed to be normally distributed in this model.
} 


\section{Table 5. RPL model with heterogeneity decomposition. Dependent variable: Choice}

\begin{tabular}{|c|c|c|c|c|}
\hline & B & $\beta *$ Transient & $\beta *$ Expat_MS & S.D. \\
\hline Variable & \multicolumn{4}{|c|}{ Coeff. (S.e.) } \\
\hline ASC & $\begin{array}{c}-1.90 * * * \\
(.205)\end{array}$ & $\begin{array}{c}-1.03 * * * \\
(.260)\end{array}$ & $\begin{array}{c}-.666 * * \\
(.305)\end{array}$ & $\begin{array}{c}3.99 * * * \\
(.183)\end{array}$ \\
\hline Distance: 200 Km & $\begin{array}{c}.711 * * * \\
(.069)\end{array}$ & $\begin{array}{c}-.197 * * \\
(.100)\end{array}$ & $\begin{array}{l}.031 \\
(.114)\end{array}$ & $\begin{array}{l}.497 * * \\
(.163)\end{array}$ \\
\hline Distance: 100 Km & $\begin{array}{c}.469 * * * \\
(.067)\end{array}$ & $\begin{array}{l}-.108 \\
(.100)\end{array}$ & $\begin{array}{c}.008 \\
(.115)\end{array}$ & $\begin{array}{l}.046 \\
(.108)\end{array}$ \\
\hline $\begin{array}{c}\text { Emission } \\
\text { Reduction: }-\mathbf{3 0 \%}\end{array}$ & $\begin{array}{l}.210 * * * \\
(.064)\end{array}$ & $\begin{array}{l}-.022 \\
(.091)\end{array}$ & $\begin{array}{l}-.041 \\
(.106)\end{array}$ & $\begin{array}{l}.157 \\
(.125)\end{array}$ \\
\hline $\begin{array}{c}\text { Emission } \\
\text { Reduction: }-20 \%\end{array}$ & $\begin{array}{l}.256^{* * * *} \\
(.056)\end{array}$ & $\begin{array}{c}-.179 * * \\
(.081)\end{array}$ & $\begin{array}{l}-.055 \\
(.093)\end{array}$ & $\begin{array}{l}.005 \\
(.101)\end{array}$ \\
\hline Parks & $\begin{array}{c}.171^{* * *} \\
(.045)\end{array}$ & $\begin{array}{l}-.074 \\
(.066)\end{array}$ & $\begin{array}{l}-.083 \\
(.076)\end{array}$ & $\begin{array}{c}.006 \\
(.082)\end{array}$ \\
\hline $\begin{array}{l}\text { Bill Reduction } \\
\text { (AED) }\end{array}$ & $\begin{array}{l}.0005 * * \\
(.0002)\end{array}$ & $\begin{array}{c}.0001 \\
(.0002)\end{array}$ & $\begin{array}{l}.0002 \\
(.0004)\end{array}$ & $\begin{array}{l}.001 * * * \\
(.0004)\end{array}$ \\
\hline Log-Likelihood & & -6991.641 & & \\
\hline R squared & & 0.188 & & \\
\hline Observations & & 7844 & & \\
\hline
\end{tabular}

Level of significance: $* 10 \%, * * 5 \%, * * * 1 \%$. Robust standard errors in parenthesis. Model with monetary attribute set as log-normal failed to converge.

Finally, we model a latent class model to confirm further the robustness of our findings. A two class model is considered and presented in Table 6, given that models with more classes did not seem to have a global optimum. The class membership was specified to be a function of 
whether expatriates are considering leaving the UAE within the next 10 years and whether respondents belong to the group of expatriates who are more satisfied in the UAE ${ }^{14}$.

Table 6. Latent class model. Dependent variable: Choice

\begin{tabular}{|c|c|c|c|c|}
\hline & ש্ & 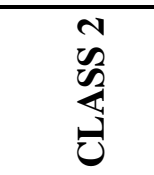 & \begin{tabular}{l}
$\vec{n}$ \\
\multirow{3}{*}{} \\
$\tilde{3}$
\end{tabular} & $\begin{array}{l}N \\
\infty \\
0 \\
0 \\
0\end{array}$ \\
\hline Variable & \multicolumn{2}{|c|}{ Coeff. (s.e.) } & \multicolumn{2}{|c|}{$\begin{array}{c}\text { Monetary valuation } \\
\text { (AED) }\end{array}$} \\
\hline ASC & $\begin{array}{c}-1.82 * * * \\
(.089)\end{array}$ & $\begin{array}{c}2.31 * * * \\
(.108)\end{array}$ & -2644.4 & 3606.6 \\
\hline Distance: $200 \mathrm{Km}$ & $\begin{array}{c}.643 * * * \\
(.048)\end{array}$ & $\begin{array}{c}.196^{* * * *} \\
(.103)\end{array}$ & 929.9 & 306.4 \\
\hline Distance: $100 \mathrm{Km}$ & $\begin{array}{c}.462 * * * \\
(.049)\end{array}$ & $\begin{array}{l}-.143 \\
(.119)\end{array}$ & 668.8 & $\rightarrow 0$ \\
\hline Emission Reduction: $20 \%$ & $\begin{array}{c}.182 * * * \\
(.045)\end{array}$ & $\begin{array}{l}.056 \\
(.109)\end{array}$ & 263.9 & $\rightarrow 0$ \\
\hline Emission Reduction: $10 \%$ & $\begin{array}{l}.156^{* * * *} \\
(.039)\end{array}$ & $\begin{array}{l}-.045 \\
(.105)\end{array}$ & 225.9 & $\rightarrow 0$ \\
\hline Parks & $\begin{array}{c}.159 * * * \\
(.032)\end{array}$ & $\begin{array}{c}.256^{* * * *} \\
(.083)\end{array}$ & 229.9 & 400.9 \\
\hline Bill Reduction (AED) & $\begin{array}{l}.0006 * * * \\
(.0001)\end{array}$ & $\begin{array}{c}.0006 * * * \\
(.0002)\end{array}$ & I & I \\
\hline \multicolumn{5}{|l|}{ Class membership function } \\
\hline Constant & $\begin{array}{c}1.15^{* * * *} \\
(.079)\end{array}$ & $0^{\mathrm{a}}$ & / & / \\
\hline Transient & $\begin{array}{c}.438 * * * \\
(.129)\end{array}$ & $0^{\mathrm{a}}$ & I & / \\
\hline Expat_MS & $\begin{array}{l}.329 * * * \\
(.151)\end{array}$ & $0^{\mathrm{a}}$ & / & / \\
\hline
\end{tabular}

14 . These two variables entering the class membership probability were also included as interactions within the RPL model with a heterogeneity decomposition. 


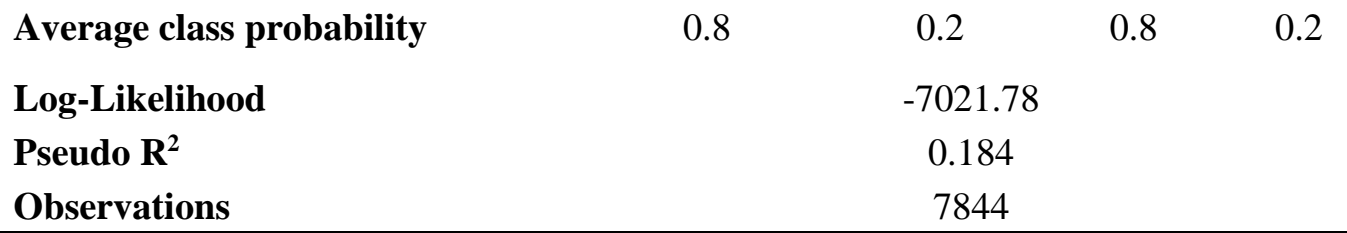

Level of significance: $* 10 \%, * * 5 \%, * * * 1 \%$. Robust standard errors in parenthesis.

The two segments are characterized as follows. The first class has a negative coefficient attached to the ASC. That is, individuals more likely to be associated with this class are more in favour of nuclear energy in the UAE. In addition, they would prefer nuclear plants be located farther away from their city of residence. Furthermore, they value emission reductions, the construction of parks and other recreational spaces, and reductions in utility bills. Those more likely to belong to class 1 are more likely to leave the UAE within the next 10 years and to be more satisfied with their life in the UAE. The second class has a positive coefficient attached to the ASC, indicating a less favorable stance towards nuclear energy for individuals allocated to this segment. This segment groups individuals who do not value the reduction of atmospheric emissions to a significant extent. However, they do value the building of parks and the provision of private benefits, namely utility bill reductions.

For internal validity purpose, after the choice experiment exercise, respondents were asked to state directly their view towards the building of nuclear plants in the UAE. A 10 points scale was employed where 1 meant 'absolutely oppose nuclear plants in the UAE' and 10 'absolutely in favor of nuclear plants in the UAE'. This permits us to validate the extent of support and opposition within each segment (Figure 5). As expected, class 2 has a higher share of clear nuclear energy opponents (25\% selecting option 1, meaning 'absolutely oppose nuclear plants in the UAE'), a higher share of neutrals (47\%) and fewer individuals in favor of nuclear energy in the country. Notably, in both segments, the share of neutral responses is substantial. Overall, segment 1 consists of respondents more favorable towards nuclear 
energy. In contrast, in segment 2, around half of the respondents are indifferent and almost 2 in 5 indicate an opposing attitude.

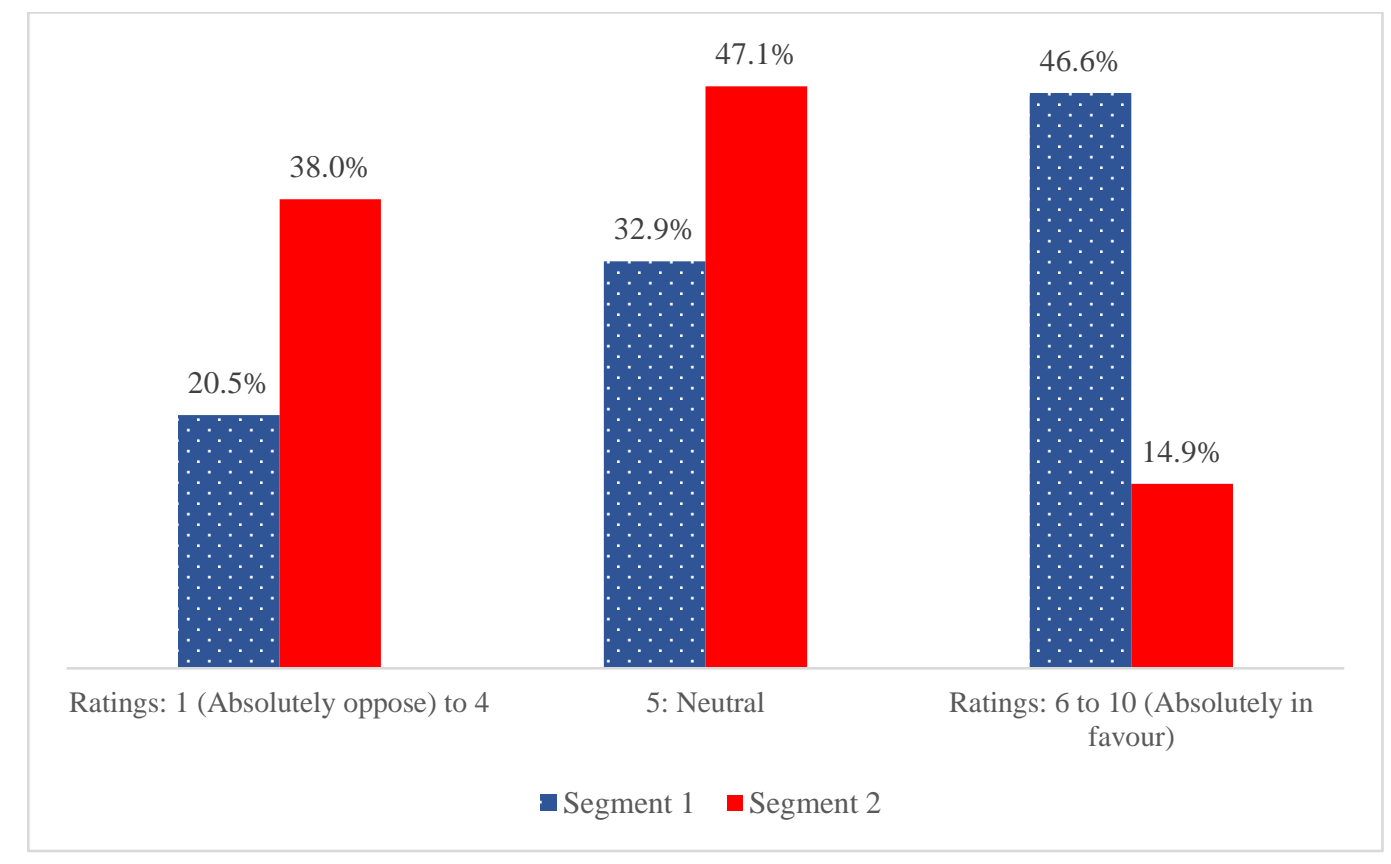

Figure 5: Views towards nuclear energy in the UAE by segment

\subsection{Factor analysis on perceived risks and benefits of nuclear energy}

In this section we conduct factor analysis to confirm the existence of the latent constructs 'Perceived risks' and 'Perceived benefits' and to test whether transient residents perceive more benefits as opposed to risks arising from nuclear energy. Table 7 presents the resulting factor loadings and uniqueness' values (Appendix C provides details on the econometrics of factor analysis). 
Table 7. Perceived Risks and Benefits: Factor loadings and uniqueness by question

\begin{tabular}{|c|c|c|c|c|c|}
\hline & \multicolumn{2}{|c|}{$\xi:$ Risks } & & \multicolumn{2}{|c|}{$\xi:$ Benefits } \\
\hline & $\begin{array}{c}\text { Factor } \\
\text { Loadings }\end{array}$ & Uniqueness & & $\begin{array}{l}\text { Factor } \\
\text { Loadings }\end{array}$ & Uniqueness \\
\hline $\begin{array}{l}\text { Catastrophic } \\
\text { accidents }\end{array}$ & 0.83 & 0.30 & $\begin{array}{l}\text { Atmospheric } \\
\text { emission } \\
\text { reduction }\end{array}$ & 0.68 & 0.53 \\
\hline $\begin{array}{l}\text { Threats to the } \\
\text { environment }\end{array}$ & 0.87 & 0.24 & $\begin{array}{l}\text { Less reliance on } \\
\text { fossil fuels }\end{array}$ & 0.73 & 0.45 \\
\hline $\begin{array}{l}\text { Threats to the } \\
\text { human health }\end{array}$ & 0.88 & 0.21 & Economic growth & 0.79 & 0.36 \\
\hline Terrorist attacks & 0.77 & 0.40 & $\begin{array}{l}\text { Energy source } \\
\text { diversification }\end{array}$ & 0.74 & 0.43 \\
\hline $\begin{array}{l}\text { Military use of } \\
\text { nuclear power }\end{array}$ & 0.75 & 0.43 & $\begin{array}{l}\text { Stable/convenient } \\
\text { energy prices }\end{array}$ & 0.60 & 0.63 \\
\hline $\begin{array}{l}\text { Risk of nuclear } \\
\text { waste disposal } \\
\text { accident }\end{array}$ & 0.83 & 0.30 & $\begin{array}{l}\text { Technology } \\
\text { development }\end{array}$ & 0.66 & 0.56 \\
\hline
\end{tabular}

Factor loading: it represents the covariance between each item and the construct.

Uniqueness: the variance that is unique to the item considered.

For both constructs, 'Risks' and 'Benefits', the factor loadings are all positive. Considering perceived risks, most of the variance in the question 'threats to human health' is explained by the construct. Instead, with regards to perceived benefits, the item 'economic growth' has the smallest uniqueness. Given the factor loadings shown in Table 7 and the answers to each of the items, it is possible to compute a score for each latent factor and for each respondent. The greater the factor loading associated with one item, the greater its weight in the computation of the individual scores. As we observed that expatriates tended to give higher ratings to both 
perceived benefits and risks, we computed the differences between benefits and risks' score factors. We refer to this measure as net perceived benefits. This allows to determine whether a given respondent scores greater on the benefits or on the risks. A greater positive difference between benefits and risks is assumed to be associated with a higher degree of acceptance, all else equal.

A series of t-tests have been performed with the aim of assessing whether these differences are significantly higher by specific groups (Table 8 ). The groups considered are 1) expatriates less satisfied in the UAE, 2) expatriates who indicated the same level of satisfaction in the UAE and in general and 3) expatriates who stated to be more satisfied in the UAE. We also repeated the tests with the subset of expatriates planning to leave the country in the next 10 years (i.e. transient), leading to additional 3 groups according to the level of life satisfaction (bottom three rows in Table 8). Expatriates more satisfied in the UAE and stating to be leaving within the next 10 years are associated with the greatest and positive mean score factor of the net perceived benefits. Instead, expatriates less satisfied in the UAE display a negative value of the difference between the score factors of benefits and risks. This indicates that transient respondents perceive more benefits as opposed to risks arising from nuclear energy, in line with their heightened support towards this energy source. 
Table 8 Mean and S.D. of net perceived benefits by group

\begin{tabular}{|c|c|c|c|c|c|c|c|c|}
\hline Segment & $\sum_{\Sigma}^{\Xi ี}$ & $\stackrel{\dot{\theta}}{\dot{s}}$ & $\begin{array}{l}\ddot{D} \\
\tilde{\Xi} \\
\tilde{D}\end{array}$ & 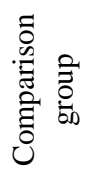 & 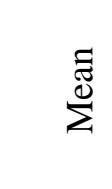 & $\dot{\varphi}$ & $\begin{array}{l}\ddot{\Xi} \\
\tilde{\Xi} \\
\tilde{\Xi}\end{array}$ & 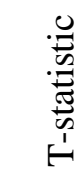 \\
\hline $\begin{array}{l}\text { Total } \\
\text { Expatriates } \\
\text { less } \\
\text { satisfied }\end{array}$ & -.154 & 1.240 & 592 & $\begin{array}{l}0 \\
\frac{0}{I I}\end{array}$ & .066 & 1.31 & 1369 & 3.85 \\
\hline $\begin{array}{l}\text { Total } \\
\text { Expatriates } \\
\text { as satisfied }\end{array}$ & .025 & 1.120 & 727 & $\frac{\ddot{D}}{\square}$ & -.014 & 1.19 & 1234 & -.726 \\
\hline $\begin{array}{l}\text { Total } \\
\text { Expatriates } \\
\text { more } \\
\text { satisfied }\end{array}$ & .190 & 1.140 & 445 & $\begin{array}{l}0 \\
\ddot{D} \\
I\end{array}$ & -.055 & 1.17 & 1516 & -3.91 \\
\hline $\begin{array}{l}\text { Transient } \\
\text { less } \\
\text { satisfied }\end{array}$ & -.174 & 1.230 & 295 & $\frac{0}{\square}$ & .062 & 1.13 & 443 & 2.67 \\
\hline $\begin{array}{l}\text { Transient as } \\
\text { satisfied }\end{array}$ & -.046 & 1.140 & 281 & $\frac{\mathscr{n}}{\square}$ & -.022 & 1.20 & 457 & .265 \\
\hline $\begin{array}{l}\text { Transient } \\
\text { more } \\
\text { satisfied }\end{array}$ & .252 & 1.100 & 162 & 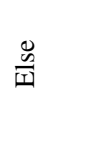 & -.112 & 1.19 & 576 & -3.49 \\
\hline
\end{tabular}

S.D.: standard deviation.

\section{Conclusion}

The UAE is in the final stages of developing its first nuclear power programme, which constitutes the first nuclear power station in the Arabian Peninsula, and the first commercial nuclear power station in the Arab World. The UAE's nuclear power program might see the first reactor begin generating electricity by 2020 . This is a crucial step in the direction of 
fulfilling increasing energy demand and moving towards decarbonizing the energy mix. The UAE has the advantage of learning from past disasters and having resources sufficient to afford world class technology (Sultan 2013). This study analyzed the extent of social acceptance of nuclear energy in the UAE and whether transiency of residence and life satisfaction shape such acceptance.

Part of the findings reveal the presence of support towards nuclear energy implementation in the UAE. First, only $11 \%$ would not want the UAE to invest in nuclear. This share is lower if compared to the analogous one found for the UK, amounting to $15 \%$; moreover, it is substantially lower when considering the case of Italy where almost half of the sampled respondents, $45 \%$, would not want the country to invest in nuclear (Contu et al. 2016; Contu and Mourato 2020). In addition, when asked to think about risks of nuclear energy in the UAE as opposed to risks of nuclear energy in general, respondents associated significantly lower risks to nuclear energy implementation in the UAE.

Additional results suggest a more cautious stand towards acceptance of nuclear energy. Only $32 \%$ of respondents believe that the risks of nuclear energy are justified by its benefits, including its contribution to limiting climate change. In addition, renewable energy sources obtained a greater share of preferences, with solar and photovoltaic coming top. This shows support towards other plans and investments the government is also undertaking such as the development of a sustainable eco-neighbourhood, Masdar City (Reiche 2010), or Abu Dhabi's goal to generate 7\% of its electricity from renewables by 2020 (Reiche 2010), and Dubai's 15\% by 2030 (Griffiths and Mills 2016).

Respondents took part in a choice experiment exercise aimed at revealing their valuations of selected attributes of hypothetical nuclear energy projects with no specific 
reference to the Barakah site, where the UAE is building four reactors. The resulting economic valuations are in line with those in the stated preference literature. We found that the potential for nuclear energy to reduce GHG emissions is positively valued, as are greater distance from the energy facility (Fimereli 2011) and the provision of public and private benefits (Strazzera et al. 2012). The latent class model findings depict a situation characterized by two distinct segments of preferences: one more in favour of nuclear energy (Segment 1) and the other one more in opposition (Segment 2). Interestingly, respondents who declared an intention to leave the UAE within 10 years and those who appear to be more satisfied with their life in the UAE seem more likely to be associated to the more nuclear energy prone segment (Segment 1). These findings are also supported by the RPL model with heterogeneity decomposition, in which transient respondents and those who are more satisfied with their life in the UAE signal a heightened level of acceptance for nuclear energy.

The results of this study highlight the presence of a link between transient residency and a lower likelihood of opposing nuclear plants developments. It also shows that residents who are more satisfied with their life in the UAE tend to be even more favorable, perceiving more benefits as opposed to risks arising from nuclear energy. This could represent a remarkable advantage for the UAE and countries with large shares of transient residents in their population as it allows considering further nuclear energy developments, exporting electricity to neighboring states and providing expertise to countries willing to embark in a nuclear programme. Results also imply that policies aimed at fostering life satisfaction can influence the way residents view government's initiatives, with positive spillovers in shaping social acceptance towards energy programmes. This is aligned with the findings of Eisasson et al. 
(2019). Future research is envisaged to assess social acceptance of nuclear energy across more GCC countries and to explore the effect of transiency of residence and life satisfaction on behaviors and willingness to cooperate in environmental or energy initiatives. 


\section{References}

Al Saadi S, Yi Y (2015) Dry storage of spent nuclear fuel in UAE- Economic aspect. Annals of Nuclear Energy 75:527-535

Ansolabehere S, Deutch J, Driscoll M, Gray P, Holdren J, Joskow P, Lester R, Moniz E, Todreas N, Beckjord E (2003) The future of nuclear power: an interdisciplinary MIT study. Retrieved from http://web.mit.edu/nuclearpower/pdf/nuclearpower-full.pdf

Ansolabehere S, Konisky D M (2009) Public attitudes toward construction of new power plants. Public Opinion Quarterly 73:566-577

Bartholomew D, Steele F, Moustaki I, Galbraith J (2008) Analysis of Multivariate Social Science Data. Chapman \& Hall

Beheshti H (2011) The prospective environmental impacts of Iran nuclear energy expansion. Energy Policy 39(10):6351-6359

Betancourt-Torcat A, Almansoori A (2015) Multi-period Optimization Model for the UAE Power Sector. Energy Procedia 75:2791-2797

Bliemer, M. C., Rose, J. M., \& Hess, S. (2008). Approximation of Bayesian efficiency in experimental choice designs. Journal of Choice Modelling, 1(1), 98-126.

Boxall, P. C., \& Adamowicz, W. L. (2002). Understanding heterogeneous preferences in random utility models: a latent class approach. Environmental and resource economics, 23(4), 421-446

Choi Y, Lee S, Cho N, Lee B (1998) Development of the public attitude model toward nuclear power in Korea. Annals of Nuclear Energy 25(12):923-936

Cicia, G, Cembalo L, Del Giudice T, Palladino A (2012) Fossil energy versus nuclear, wind, solar and agricultural biomass: Insights from an Italian national survey," Energy Policy 42:59-66

Contu, D. (2018) Modeling individual preferences towards nuclear energy. PhD Thesis, The London School of Economics and Political Science 
Contu, D., Strazzera, E., \& Mourato, S. (2016). Modeling individual preferences for energy sources: The case of IV generation nuclear energy in Italy. Ecological Economics, 127, 3758.

Contu, D., Mourato, S. (2020). Combining choice experiment with contingent valuation data: Individual preferences and views towards IV generation nuclear energy in the UK. Energy Policy 136111032

De Boer C, Catsburg I (1988) A report: the impact of nuclear accidents on attitudes toward nuclear energy. The Public Opinion Quarterly 52(2):254-261

Dolan P, Metcalfe R (2012) Valuing health: a brief report on subjective well-being versus preferences. Medical Decision Making 32 (4):578-582

Early B R (2010) Acquiring Foreign Nuclear Assistance in the Middle East: Strategic Lessons from the United Arab Emirates. Nonproliferation Review 17(2):259-280

El-Katiri L (2012) The GCC and the nuclear question. Oxford Energy Comment-The Oxford Institute for Energy Studies. Retrieved from https://www.oxfordenergy.org/wpcms/wpcontent/uploads/2012/12/The-GCC-and-the-Nuclear-Question.pdf

ENEC (2011) UAE poll shows continued support for peaceful nuclear energy program. Retrieved from http://www.enec.gov.ae/media-centre/news/content/uae-poll-showscontinued-support-for-peaceful-nuclear-energy-program

ENEC (2014) ENEC to host open public forums in Abu Dhabi and Silla. http://www.enec.gov.ae/media-centre/news/content/enec-to-host-open-public-forums-in-abudhabi-and-silla

Ertör - Akyazi P, Adaman F, Özkaynak B, Zenginobuz Ü (2012) Citizens' preferences on nuclear and renewable energy sources: Evidence from Turkey. Energy Policy 47:309-320

Fairlie I (2013) A hypothesis to explain childhood cancers near nuclear plants. Journal of Environmental Radioactivity 133:10-17 
Fimereli, E (2011). Towards a low-carbon economy: an investigation of the public acceptability of and preferences for low-carbon energy options in the UK (Doctoral dissertation, Imperial College London)

Forstenlechner I, Rutledge E J (2011) The GCC's “Demographic Imbalance”: perceptions, realities and policy options. Middle East Policy 18 (4):25-43

Globescan (2005) Global Public Opinion on nuclear issues and the IAEA. Final report from 18 countries. Retrieved from

http://large.stanford.edu/courses/2015/ph241/1lanos1/docs/globescan.pdf

Greenberg M (2009) Energy sources, public policy, and public preferences: Analysis of US national and site-specific data. Energy Policy 37:3242-3249

Greenberg M, Truelove H B (2011) Energy choices and risk beliefs: Is it just global warming and fear of a nuclear power plant accident? Risk Analysis 31:819-831

Greene W, Hensher D (2003) A latent class model for discrete choice analysis: contrasts with mixed logit. Transportation Research Part B: Methodological 37(8):681-698

Gregory R, Kunreuther H, Easterling D, Richards K (1991) Incentives policies to site hazardous waste facilities. Risk Analysis 11(4):667-675

Griffiths S, Mills R (2016) Potential of rooftop solar photovoltaics in the energy system evolution of the United Arab Emirates. Energy Strategy Reviews 9:1-7

Groot JI de, Steg L (2008) Value orientations to explain beliefs related to environmental significant behavior. How to measure egoistic, altruistic, and biospheric value orientations. Environment and Behavior 40:330-355

Groot JI de, Steg L, Poortinga W (2013) Values, perceived risks and benefits, and acceptability of nuclear energy. Risk Analysis 33(2):307-317

Hammond G (1996) Nuclear energy into the twenty-first century. Applied Energy 54(4):327334

Hanley N, Mourato S, Wright R E (2001) Choice modelling approaches: a superior alternative for environmental valuation? Journal of economic surveys 15(3):435-462 
Hensher D A, Greene W H (2003) The mixed logit model: The state of practice. Transportation 30:133-176

Hills R C, Atkins P W B (2013) Cultural identity and convergence on western attitudes and beliefs in the United Arab Emirates. International Journal of Cross Cultural Management 13(2):193-213

Hole, A. R., Kolstad, J. R. (2012). Mixed logit estimation of willingness to pay distributions: a comparison of models in preference and WTP space using data from a health-related choice experiment. Empirical Economics, 42(2), 445-469

Jayaraman R, Colapinto C, La Torre D, Malik T (2015) Multi-criteria model for sustainable development using goal programming applied to the United Arab Emirates. Energy Policy $87: 447-454$

Jun E, Kim W J, Jeong Y H, Chang S H (2010) Measuring the social value of nuclear energy using contingent valuation methodology. Energy Policy 38:1470-1476

Itaoka, K., Saito, A., Krupnick, A., Adamowicz, W., \& Taniguchi, T. (2006). The effect of risk characteristics on the willingness to pay for mortality risk reductions from electric power generation. Environmental and Resource Economics, 33(3), 371-398

Kahneman D, Krueger A B (2006) Developments in the measurement of subjective wellbeing. The Journal of Economic Perspectives 20:3-24

Kato T (2006) Effectiveness of compensation for the risk of living near a nuclear power plant station: A natural experiment. III World Congress of Environmental and Resource Economics, Kyoto Japan

Koch N (2016) Is nationalism just for nationals? Civic nationalism for non-citizens and celebrating National Day in Qatar and the UAE. Political Geography 54:43-53

Kovacs P, Gordelier S (2009) Nuclear power and the public. Facts and opinions, NEA News 2009 No. 27.1

Lancaster K J (1966) A new approach to consumer theory. The Journal of Political Economy 74(2):132-157 
Letcher T, Vallero D (2019) Waste $2^{\text {nd }}$ Edition-A Handbook for Management. Academic Press

Levinson A (2012) Valuing public goods using happiness data: The case of air quality. Journal of Public Economics 96 (9-10):869-880

Louviere J J, Hensher D.A., Swait J. (2000) Stated choice methods: analysis and application, Cambridge University Press, Cambridge

Mansfield C, Houtven G V, Huber J (2002) Compensating for public harms: why public goods are preferred to money. Land Economics 78(3):368-389

MacKerron G (2012) Happiness economics from 35000 feet. Journal of Economic Surveys 26:705-735

MacKerron G, Mourato S (2013) Happiness is greater in natural environments. Global Environmental Change 23:992-1000

McFadden D (1974). Conditional logit analysis of quantitative choice behaviour. In: Zarembka, P., Frontiers in Econometrics. Academic Press, New York

McFadden D, Train K (2000) Mixed MNL models for discrete response. Journal of Applied Econometrics 15:447-470

Meijer E, Rouwendal J (2006) Measuring welfare effects in models with random coefficients. Journal of Applied Econometrics 21(2):227-244

Mezher T, Dawelbait, G, Abbas Z (2012) Renewable energy policy options for Abu Dhabi: Drivers and barriers. Energy Policy 42:315-328

OECD (2010) Public attitudes to nuclear power. Retrieved from https://www.oecdnea.org/ndd/reports/2010/nea6859-public-attitudes.pdf

Pidgeon N F, Lorenzoni I, Poortinga W (2008) Climate change or nuclear power-No thanks! A quantitative study of public perceptions and risk framing in Britain. Global Environmental Change 18(1):69-85

Reiche (2010) Renewable energy policies in the Gulf countries: A case study of the carbonneutral 'Masdar City' in Abu Dhabi. Energy Policy 38(1):378-382 
Revelt, D, Train K (1998). Mixed logit with repeated choices: households' choices of appliance efficiency level. Review of economics and statistics, 80(4), 647-657

Rakotonarivo O S, Schaafsma M, Hockley N (2016) A systematic review of the reliability and validity of discrete choice experiments in valuing non-market environmental goods. Journal of Environmental Management 183(1):98-109

Rosa E, Dunlap R (1994) Poll trends: nuclear power: three decades of public opinion. The Public Opinion Quarterly 58(2):295-324

Rose J M, Bliemer M C J (2009) Constructing efficient stated choice experimental designs. Transport Reviews 29(5):587-617

Schneider M, Froggatt A, Hazemann J, Katsuta T, Ramana M V, Fairlie I, Maltini F, Thomas S (2016) The world nuclear industry Status Report 2016

Siegrist M, Cvetkovich G (2000) Perception of hazards: The role of social trust and knowledge. Risk Analysis 20(5):713-720

Siegrist M, Cvetkovich G, Roth C (2000) Salient value similarity, social trust, and risk/benefit perception. Risk Analysis 20:353-362

Strategic Comments (2010) UAE leads Gulf nuclear-power plans. 16(2):1-3

Strazzera E, Mura M, Contu D (2012) Combining choice experiments with psychometric scales to assess the social acceptability of wind Energy projects: A latent class approach. Energy Policy 48:334-347

Sultan N (2013) The challenge of shale to the post-oil dreams of the Arab Gulf. Energy Policy 60:13-20

Train KE, Weeks M (2005) Discrete choice models in preference space and willingness-topay space. In: Scarpa R, Alberini A (eds) Application of simulation methods in environmental and resource economics. Springer, Dordrecht, pp 1-16

Van den Berg B, Ferrer-I-Carbonell A (2007) Monetary valuation of informal care: the wellbeing valuation method. Health Economics 16(11):1227-44

Venables D, Pidgeon N F, Parkhill K A, Henwood K L, Simmons P (2012) Living with nuclear power: sense of place, proximity, and risk perceptions in local host communities. 
Journal of Environmental Psychology 32(4):371-383

Visschers V H M, Keller C, Siegrist M (2011) Climate change benefits and energy supply benefits as determinants of acceptance of nuclear power stations: investigating an exploratory model. Energy Policy 39(6):3621-3629

Weisser D, Howells M, Rogner H (2008) Nuclear power and post-2012 energy and climate change policies. Environmental Science and Policy 11:467-477

Wu Y (2017) Public acceptance of constructing coastal/inland nuclear power plants in postFukushima China. Energy Policy 10:484-491

World Happiness Report (2016) http://worldhappiness.report/

Yamane F, Matsushita K, Ohgaki H, Asano K (2011) Social factors affecting economic welfare of the residents around nuclear plants in Japan. Energy Procedia 9:619-629

Zhu W, Wei J, Zhao D (2016) Anti-nuclear behavioral intentions: The role of perceived knowledge, information processing, and risk perception. Energy Policy 88:168-177 


\section{Appendix A}

Table A1. Variables used in the CE econometric models

Choice Experiments-

Utility function

Variables

ASC

Distance 200 Km

Distance 100 Km

Distance 50 Km

Emission Reduction: -

$20 \%$

Emission Reduction: -

$10 \%$

Parks

Bill Reduction
Type

$\begin{array}{lcccc} & \text { Mean } & \text { S.D. } & \text { Min } & \text { Max } \\ \text { Dichotomous } & 0.30 & 0.46 & 0.00 & 1.00 \\ \text { Dichotomous } & 0.17 & 0.38 & 0.00 & 1.00 \\ \text { Dichotomous } & 0.17 & 0.37 & 0.00 & 1.00 \\ \text { Dichotomous } & 0.15 & 0.36 & 0.00 & 1.00 \\ \text { Dichotomous } & & & & \\ & 0.20 & 0.40 & 0.00 & 1.00\end{array}$

Dichotomous

$\begin{array}{llll}0.26 & 0.44 & 0.00 & 1.00\end{array}$

$\begin{array}{llll}0.34 & 0.47 & 0.00 & 1.00\end{array}$

AED/household/year

86.9

140.3

0.00

900

Choice Experiments-Segment membership Variables

Transient

Dichotomous

.38

.48

0.00

1.00

Expat_MS ${ }^{\mathbf{b}}$

Dichotomous

.23

.42

0.00

1.00

Bill reduction was expressed in percentages in the choice tasks; these values were multiplied times the average annual electricity bill of the sampled respondents in order to obtain the AED/household/year unit.

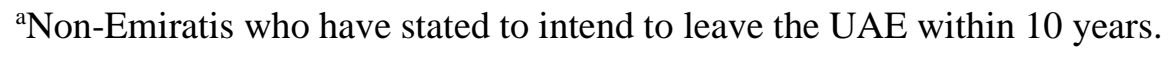

${ }^{\mathrm{b}}$ Non-Emiratis who stated to be more satisfied with their life in the UAE. 


\section{Appendix B}

\section{B1 Key questions, scales, information presented}

This section presents key questions used in this study. Answers to these questions were used to measure latent constructs, both in a confirmatory and exploratory approach, or to support in multivariate analysis as well as serve as predictors.

\section{B1.1 Life satisfaction and transiency of residence}

The questions on life satisfaction and transiency of residence are of paramount importance. Two questions on life satisfaction were asked. Respondents were presented with a scale ranging from 1 to 10 , where 1 meant 'Not at all satisfied' and 10 'Extremely satisfied'. They were asked to rate thinking about how satisfied they were with their life in general and, separately, with their life in the UAE. This can be defined as the evaluative account of wellbeing (Dolan and Metcalcfe 2012); whilst it can be affected by recall bias, it seems an apt indicator of whether the individual is satisfied in relation to her life in the country, as a whole. In order to measure transiency, we opted for a single question asking the following: 'How long are you planning to stay in the UAE?'. Possible options were presented as intervals, from 'less than 3 months' to 'more than 10 years'. The minimum was set to take into account the possibility of respondents about to leave the Country due to, for instance, job loss (notice period in the UAE is a minimum of a month according to UAE Labor Law, article 117). We kept the upper option to 'more than 10 years' to maintain the list short and reasonable in terms of time period considered. 
How long are you planning to stay in the UAE?

Less than 3 months

$3-6$ months

$6-12$ months

$1-2$ years

$3-4$ years

$5-6$ years

$7-10$ years

More than 10 years

I do not plan to move out of the UAE

Other (please specify)

I do not know

Figure B.1: Question to measure transiency

Please think for a moment about how satisfied are you with your life. On a scale from 1 to 10 , where 1 means "Not at all satisfied" and 10 means "Extremely satisfied",

$\begin{array}{cccccccccc}\begin{array}{c}\text { 1: Not at } \\ \text { all } \\ \text { satisfied }\end{array} & 2 & 3 & 4 & 5 & 6 & 7 & 8 & 9 & \begin{array}{c}\text { 10: Very } \\ \text { satisfied }\end{array} \\ 0 & 0 & 0 & 0 & 0 & 0 & 0 & 0 & 0 & 0 \\ 0 & 0 & 0 & 0 & 0 & 0 & 0 & 0 & 0 & 0\end{array}$

Figure B.2: Question to measure life satisfaction 


\section{B.1.2 Questions on preferences towards energy sources}

Respondents were asked to state how much the country they reside in should invest in different energy sources. This question is adapted from Pidgeon et al. $(2008)^{15}$, where instead of an agreement and disagreement scale respondents were asked to pick between invest 'nothing' and invest 'a lot'. Following the pilots, this format seemed to be easier for the respondents to grasp.

\begin{tabular}{|c|c|c|c|c|c|}
\hline & Nothing & A little & Some & A lot & I don't know \\
\hline Oil & $\bigcirc$ & 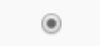 & 0 & $\bigcirc$ & $\bigcirc$ \\
\hline Gas & $\bigcirc$ & $\bigcirc$ & $\bullet$ & $\bigcirc$ & $\bigcirc$ \\
\hline Geothermal & 0 & 0 & O & $\bullet$ & $\bigcirc$ \\
\hline Clean Coal & $\bigcirc$ & 0 & 0 & $\bullet$ & $\bigcirc$ \\
\hline Traditional Coal & 0 & $\bullet$ & 0 & 0 & 0 \\
\hline Solar/Photovoltaic & $\bigcirc$ & $\bullet$ & 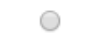 & 0 & $\bigcirc$ \\
\hline Nuclear & 0 & $\bullet$ & O & $\bigcirc$ & $\bigcirc$ \\
\hline Wind & $\bigcirc$ & $\bigcirc$ & $\bullet$ & 0 & $\bigcirc$ \\
\hline Biomass & 0 & $\bigcirc$ & O) & 0 & $\bigcirc$ \\
\hline
\end{tabular}

Figure B.3: Questions on preference towards energy sources

\section{B.1.3 Perceived risks and benefits of nuclear energy}

Figures B.1.4 and B.1.5 show the corresponding screen shown as part of the study. Respondents answered the set of questions on risks and benefits twice: once whilst thinking about nuclear energy in general, and then considering nuclear energy in the UAE. A 5 points

\footnotetext{
15 To what extent do you agree or disagree that the following energy sources will make a substantial contribution to reliable and secure supplies of electricity in Britain in the future?
} 
scales for the UAE was used (rather than 7 used in Contu 2018). This reduction was chosen to limit the amount of information to process, given the that respondents were asked to answer twice each set.

In your opinion, how likely are the following RISKS associated with nuclear energy in the UAE? Nuclear energy in this context is heat, steam and electricity generated by nuclear reactors, fuelled by enriched uranium. The UAE peaceful nuclear energy programme will produce nearly a quarter of the nation's electricity needs by 2020.

\begin{tabular}{|c|c|c|c|c|c|}
\hline & Very unlikely & Unlikely & Neutral & Likely & Very likely \\
\hline Risk of catastrophic accidents & $\bigcirc$ & $\bigcirc$ & $\bigcirc$ & $\bigcirc$ & $\bigcirc$ \\
\hline Damage/threats to the environment & $\bigcirc$ & $\bigcirc$ & $\bigcirc$ & $\bigcirc$ & $\bigcirc$ \\
\hline Damage/threats to human health & $\bigcirc$ & $\bigcirc$ & $\bigcirc$ & 0 & $\bigcirc$ \\
\hline Terrorist attacks & $\bigcirc$ & $\bigcirc$ & $\bigcirc$ & $\bigcirc$ & $\bigcirc$ \\
\hline Military use of nuclear power & $\bigcirc$ & $\bigcirc$ & $\bigcirc$ & $\bigcirc$ & $\bigcirc$ \\
\hline Nuclear waste disposal accidents & $\bigcirc$ & $\bigcirc$ & $\bigcirc$ & $\bigcirc$ & $\bigcirc$ \\
\hline
\end{tabular}

\section{Figure B.1.4: Questions on perceived risks of nuclear energy}

In your opinion, how likely are the following BENEFITS associated with nuclear energy in the UAE? Nuclear energy in this
context is heat, steam and electricity generated by nuclear reactors, fuelled by enriched uranium. The UAE peaceful nuclear
energy programme will produce nearly a quarter of the nation's electricity needs by 2020 .
\[ \text { Very unlikely } \quad \text { Unlikely } \]
Atmospheric emission reduction
Less reliance on fossil fuels
Economic growth
Energy sources diversification
Stable/convenient energy prices
Technology development/innovation

\section{Figure B.1.5: Questions on perceived benefits of nuclear energy}




\section{Appendix C Statistical and Econometric models}

\section{C.1 Analysis of choice experiment data}

We measure social acceptance of nuclear energy by means of a choice experiment exercise so as to indirectly measure willingness to accept the construction of nuclear plants in the UAE. This methodology is rooted on the Lancaster's theory of value (Lancaster 1966) and on the Random Utility theory (McFadden 1974). Respondents were presented with pairs of 4 scenarios and in each choice situation they were asked to select their preferred one, or none of them. Each option in each scenario is associated to a set of attributes and levels. Each individual $(i)$ is assumed to evaluate the alternatives ( $\mathrm{j}$ ) and choose the one for which its utility is maximized. In turn, the utility function is divided into a deterministic $\left(V_{i j}\right)$ and random component $\left(\varepsilon_{i j}\right)$ :

$U_{i j}=V_{i j}+\varepsilon_{i j}$

The deterministic component is a function of attributes' matrix $\mathbf{x}$ and the associated preference parameters, represented by the vector of coefficients $\boldsymbol{\beta}$ :

$$
V_{i t, j}=\mathrm{f}\left(\mathbf{x}_{i t, j}^{\prime} \boldsymbol{\beta}\right)
$$

We model preference heterogeneity using two models established in the choice modeling literature: the RPL or mixed logit model (Hensher and Green 2003) and Latent Class model (Boxall and Adamowicz 2002, Greene and Hensher 2003) ${ }^{16}$. The former is based on the assumption of a continuous distribution across individuals, namely estimating individual specific effects $\boldsymbol{\beta}_{\boldsymbol{i}}$, with the choice probabilities as follows:

\footnotetext{
${ }^{16}$ We also estimated MNL models that assumes preference homogeneity.
} 
$P_{i j t}=\frac{\exp \left(\mathbf{x}_{i t, j}^{\prime} \boldsymbol{\beta}_{i}\right)}{\sum_{j} \exp \left(\mathbf{x}_{i t, j}^{\prime} \boldsymbol{\beta}_{i}\right)}$

Formally, for each of the K parameters assumed to be continuously distributed, the vector of individual coefficients is as follows:

$\beta_{i}=\beta+\Delta \mathbf{z}_{\mathbf{i}}+\Gamma \mathbf{m}_{\mathbf{i}}$

where $\mathbf{z}_{\mathbf{i}}$ is a vector of individual characteristics affecting the mean of $\boldsymbol{\beta}_{\mathbf{i}}$, and $\Delta$ indicates the matrix of parameters to be estimated. The random effect $\mathbf{m}_{\mathbf{i}}$ has the following expected value and variance:

$E\left[\mathbf{m}_{\mathrm{i}}\right]=0, \operatorname{Var}\left[\mathbf{m}_{\mathrm{i}}\right]=\underline{\Sigma}=\operatorname{diag}\left[\sigma_{1}, \ldots, \sigma_{k}\right]$

The analyst has to specify the distribution of the random parameters. Furthermore, $\boldsymbol{\Gamma}$ represents the lower triangular matrix containing the variances and covariances of the joint distribution of $\boldsymbol{\beta}_{\mathbf{i}}$, to be estimated. Giving that respondents are engaged in a sequence of choices, the conditional distribution is given by:

$P_{i}\left|\mathbf{m}_{i}=\prod_{t=1}^{T} P_{i t}\right| \mathbf{m}_{i}$

In turn, the unconditional probability, obtained by integrating $\mathrm{m}_{\mathrm{i}}$ out of the joint probability is as follows:

$P_{i}=\int_{\mathbf{m} i} P_{i} \mid \mathbf{m}_{i} h\left(\mathbf{m}_{i}\right) \mathrm{d} \mathbf{m}_{i}$

where $h\left(\mathbf{m}_{i}\right)$ stands for the density of $\mathbf{m}_{i}$. As normally this integral does not have a close form solution, estimation requires maximizing a simulated log likelihood approach (McFadden and Train 2000):

$\ln L_{s}=\sum_{\mathrm{i}=1}^{N} \ln \left[\frac{1}{R} \ln \mathrm{P}_{\mathrm{i}} \mid \mathbf{m}_{\mathrm{ir}}\right]$ 
with $\mathbf{m}_{\text {ir }}$ being a simulated draw from the distribution hypothesized, out of the total $\mathrm{R}$ draws. The simulation process allows to produce an average over a high number of draws, de facto replacing the continuous integral by summation. This model was estimated with the command MIXLOGIT in STATA, with a minimum of 500 Halton draws set.

Instead, when it comes to the Latent Class model, heterogeneity is modeled in a discrete fashion. The key behavioral model is once again a logit model for discrete choice, but with coefficients $\boldsymbol{\beta}_{\mathbf{s}}$ being segment specific:

$P_{i t, j \mid s}=\frac{\exp \left(\mathbf{x}_{i t, j}^{\prime} \boldsymbol{\beta}_{s}\right)}{\sum_{j} \exp \left(\mathbf{x}_{i t, j}^{\prime} \boldsymbol{\beta}_{s}\right)}$

The probability of a specific choice being made by the respondent i as $P_{i t \mid s}(j)$. Assuming the $\mathrm{T}$ choices are independent given the class allocation, the joint probability of the set of choices is given by:

$P_{i \mid s}=\prod_{t}^{T} P_{i t \mid s}$

With regards to the class assignment, whose outcome needs to be between 0 and 1 , a common formulation employed is the multinomial logit:

$\mathrm{H}_{\mathrm{is}}=\frac{\exp \left(\mathbf{z}_{i}^{\prime} \boldsymbol{\theta}_{s}\right)}{\sum_{s} \exp \left(\mathbf{z}_{i}^{\prime} \boldsymbol{\theta}_{s}\right)}$

where $\mathbf{z}_{\mathbf{i}}$ represents a set of individual characteristics that might affect class allocation. In order for the model to be identified, the parameters of one of the segments have to be normalized to zero. Furthermore, the unconditional choice probability for each individual is given by:

$P_{i}=\sum_{S}^{S} H_{i s} P_{i \mid s}$ 
Finally, the log likelihood for the whole sample, to be maximised with respect to $\boldsymbol{\beta}_{\boldsymbol{s}}$ and $\boldsymbol{\theta}_{\boldsymbol{s}}$, is as follows:

$\ln L=\sum_{i}^{N} \ln P_{i}=\sum_{i}^{N} \ln \left[\sum_{S}^{S} H_{i s}\left(\prod_{t}^{T} P_{i t \mid s}\right)\right]$

The analyst has to specify the number of classes to be estimated. Next, given the goodness of fit, significance of parameters and overall analyst's judgement, the choice of the final model can be made. The latent class models were estimated in Limdep NLOGIT. Different starting values were specified to check for presence of local maxima.

Irrespective of the model estimated, with a linear in parameters utility function, the coefficients estimated directly represent marginal utilities, and their ratio indicates a marginal rate of substitution. When the denominator is the coefficient attached to the monetary attribute, the resulting ratio represents a monetary valuation (MV). Given K attributes and a monetary attribute $\mathrm{m}$, in the context of the MNL model the monetary valuation will be unique for each attribute or level of the same:

$M V_{k}=\left|\frac{\beta_{k}}{\beta_{m}}\right|$

Instead, in the context of a latent class model, this will be conditional on a given segment:

$$
M V_{k \mid s}=\left|\frac{\beta_{k \mid s}}{\beta_{m \mid s}}\right|
$$

\section{C.2 Analysis of psychometric data ${ }^{17}$}

Perceived risks and benefits are in this study seen as latent factors. These are measured by means of questionnaire items, which then form the inputs of factor analyses. Formally, given

\footnotetext{
${ }^{17}$ Based on Bartholomew et al. (2008).
} 
a set of $\mathrm{k}$ items relatable to a set of constructs, factor analysis involves estimating the following equation for each item i:

$v_{i}=\sum_{j} \lambda_{i j} \xi_{j}+\delta_{i}$

where $v_{i}$ represents the item, $\lambda_{i j}$ the factor loadings, $\xi_{j}$ the latent construct, and $\delta_{i}$ are the specific factors. The model implies the following variances:

$$
\operatorname{Var}\left(v_{i}\right)=\left(\sum_{j} \lambda_{i j}{ }^{2}\right)+\theta_{i i}
$$

The loadings $\lambda_{i}$ can be interpreted as the covariance between each $v_{i}$ and the latent factor $\xi_{j}$. The unique variance of each item is represented by $\theta_{i i}$. The complement of uniqueness represents the communality, whose mean is the proportion of total variance explained by the factor. Given the factor loading obtained, it is possible to compute individual scores:

$$
\hat{v}_{i}=\sum_{i}\left(\lambda_{i j} / \theta_{i i}\right) v_{i}
$$

